\title{
DNA nanomachines and their functional evolution
}

\author{
Huajie Liu $\dagger$ and Dongsheng Liu* \\ Received (in Cambridge. UK) 17th December 2008, Accepted 10th March 2009 \\ First published as an Advance Article on the web 9th April 2009 \\ DOI: $10.1039 / b 822719 e$
}

Since the establishment of the Watson-Crick model more than five decades ago, the understandings of DNA structures are well sufficient to enable applications of DNA in designing and assembling two-dimensional (2D) and three-dimensional (3D) structures at the nanoscale. Furthermore, the conformational switchability of DNA also enables the fabrication of nanoscale molecular machines, which can perform movements upon stimuli. In this article, we will summarize the present efforts on constructions of DNA nanomachines based on different driven mechanisms, and further discuss their evolutional processes, in order to find applications and future development directions.

\section{Introduction}

DNA has been seen to play an extraordinary important role in life science more than five decades since the establishment of the Watson-Crick model. Tracing back to its chemical essence, DNA has also received attention in material sciences, especially in nanoscience. ${ }^{1}$ Based on specific base-pair formation and programmable sequence, DNA nanostructure assembly, pioneered by Seeman et al. ${ }^{2-6}$ in the 1980s, has now reached the stage of facile fabrication of complicated $2 \mathrm{D}^{7-12}$ and even 3D nanostructures via designed hybridization processes. $^{13-16}$ However, compared to these static nanostructures, a more challenging aspect in this field is fabricating nanomachines which can perform nanoscale movements in

National Centre for NanoScience \& Technology, No. 11 Beiyitiao, Zhongguancun, Beijing, 100190,China.E-mail: liuds@nanoctr.cn; Fax: + 86-10-62656765: Tel: + 86-10-82545589

$\dagger$ Current address: Centre for DNA Nanotechnology at Department of Chemistry and iNANO, University of Aarhus, Denmark. response to external stimuli. ${ }^{17-20}$ Although protein is the material chosen by Nature to facilitate nanomachines in living beings, ${ }^{21,22}$ the clearer structures, established synthesis and modification methods and clearer driven mechanisms of DNA nanomachines, have been demonstrated to be of interest for material research as well as theoretical studies. From the first effort to control DNA motion, ${ }^{23}$ the last decade has witnessed an explosion of interest and effort in this field. ${ }^{24-29}$

In this review, we have sorted out several basic DNA nanomachine types by driven mechanism. The consequent evolution on the power input method to improve the kinetics of each type is summarized to give a perspective on their development trends. We then highlight the efforts on measuring the mechanical outputs of DNA nanomachines as well as employing these outputs to achieve new functional devices and materials. Through these analyses, we will try to provide some perspectives on the development of DNA nanomachines in the near future.

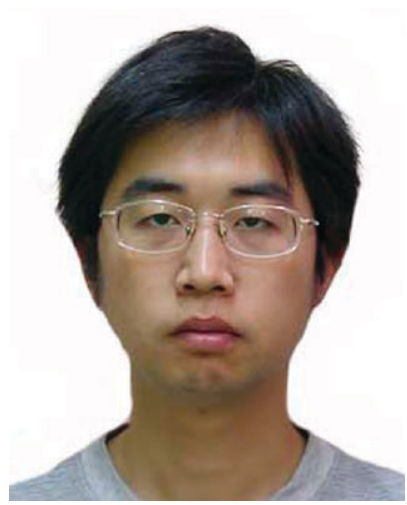

Huajie Liu
Dr Huajie Liu received his BS in applied chemistry and $M S$ in inorganic chemistry at Tongji University. From 2005 to 2008 , he was a PhD student under the supervision of Prof. Dongsheng Liu at the National Center for Nanoscience and Technology. During his $P h D$ period, he worked on developing new control-modes and applications of DNA nanomotors. He is currently working as a postdoctoral fellow with Prof. Kurt $V$. Gothelf at the University of Aarhus, where his research concentrates on DNA directed assembly of nanomaterials.

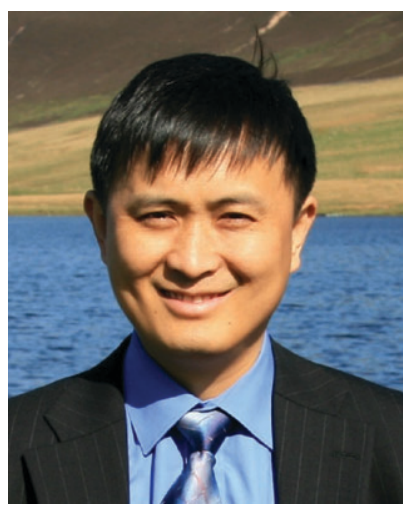

Dongsheng Liu
Professor Dongsheng Liu graduated from the University of Science and Technology of China with a BS degree in 1993. After working in the Institute of Chemistry, Chinese Academy of Sciences for six years, he went to the Hong Kong Polytechnic University and finished his $P h D$ there under the supervision of Professor A. S. C. Chan in 2002. He moved to the UK afterwards and worked as a postdoc research associate in NanoIRC and Department of Chemistry, Cambridge University. In 2005, he took the position as a principal investigator in the National Centre for NanoScience and Technology, China. His researches are mainly focused on using biomolecules to fabricate nanostructures and nanodevices. 


\section{Prototype DNA nanomachines}

A machine could be defined as any device that uses energy to perform some activity, e.g. mechanical movement. We also use word "motor" to describe a device that converts various forms of energy into kinetic energy for mechanical work. As outlined in an editorial ${ }^{18}$ by Stoddart: "organization, the power source, and work of a repetitive nature" are the most important characteristics of a molecular machine. From this point of view, the DNA nanomachine could be regarded as a kind of molecular machine that is made up of assembled DNA structures integrated with an external stimuli responding mechanism. Thus all established DNA nanomachines could be sorted into several catalogues by their original driven mechanisms. In the following, we will summarize the variation of each prototype to map their development trends, respectively.

\section{DNA nanomachines controlled by "fuel-strands"}

It is well known that a short DNA strand can be replaced by a longer strand to form a more stable duplex, which is called "chain-exchange reaction" or "strand-exchange reaction". This reaction has been employed to induce motions to DNA-based nanostructures. In 2000, Yurke et al. reported the first hybridization energy-driven DNA nanomachine which resembles a pair of tweezers (Fig. 1). ${ }^{30}$ Their device is assembled by three single-strands which can form two rigid duplex arms connected by a hinge section and two dangling ends linked to arms. At the "open" state, two ends of the arms are thermodynamically separated. To "close" the tweezers, an additional fourth strand $\mathbf{F}$ hybridizes with both dangling ends and pulls the two arms together. The device could be reopened by $\mathbf{F}$ 's fully complementary strand $\mathbf{F}^{\prime}$ because duplex $\mathbf{F F}^{\prime}$ has a lower free energy (note an overhang section on $\mathbf{F}$ is the starting point for $\mathbf{F F}^{\prime}$ hybridization). The alternating addition of $\mathbf{F}$ and $\mathbf{F}^{\prime}$ will cycle the machine and produce duplex $\mathbf{F F}^{\prime}$ as waste.

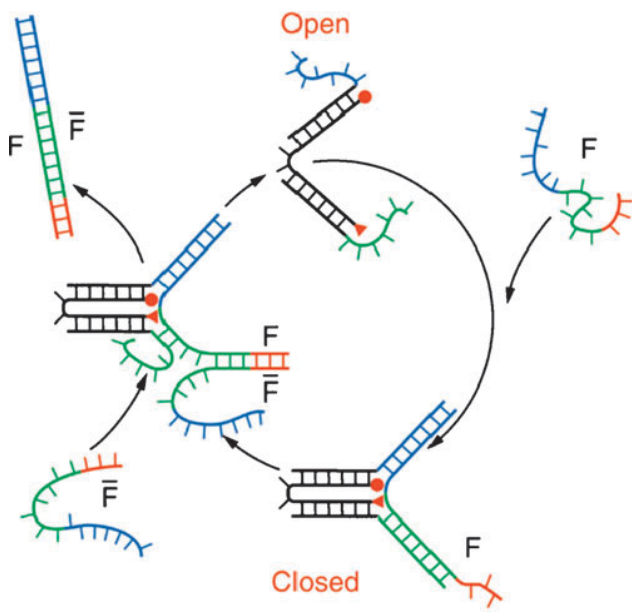

Fig. 1 DNA tweezers controlled by "fuel" and "anti-fuel" strands. Fuel strand $\mathbf{F}$ hybridizes with the dangling ends of the open state machine (shown in blue and green) to pull the tweezers closed. Hybridization with the overhang section of $\mathbf{F}$ (red) allows anti-fuel strand $\mathbf{F}^{\prime}$ to remove $\mathbf{F}$ from the tweezers, forming a double-stranded waste product $\mathbf{F F}^{\prime}$ and allowing the tweezers to open (reprinted with permission from ref. 30; copyright 2000, Nature Publishing Group).
Since the machine is powered by competitive hybridization, the authors called the stimuli, DNA $\mathbf{F}$ and $\mathbf{F}^{\prime}$, as "fuel" and "anti-fuel". Overall, one switching is able to generate a force of about $15 \mathrm{pN}$, with a maximum separation of the arm ends of about $6 \mathrm{~nm}$ or $50^{\circ}$; FRET and recently sp-FRET ${ }^{31}$ techniques have been used to monitor the motions. The modifications of this design in following years have led to some variants: an actuator ${ }^{32}$ and a three-state nanomachine ${ }^{33}$ that looks like a combination of tweezers and actuator.

This fuel-strands strategy has also been employed to drive different DNA assemblies to move: Yan and Seeman proposed a robust DNA nanomachine ${ }^{34}$ whose motions are between two topological motifs: four-stranded PX and $\mathrm{JX}_{2}$ complexes. The addition of DNA fuels will induce a four-step rotation. A noticeable experimental detail is the use of biotinylated fuel-strands to remove duplex wastes. By covalently linking $\mathrm{PX}-\mathrm{JX}_{2}$ machines linearly, the rotations of DNA machines in these arrays could be controlled synchronously and be visualized by atomic force microscopy (AFM). RNA has also been exploited to control this device. ${ }^{35}$ Extension of this two-state machine to a three-state one has recently been done by the same group. ${ }^{36}$

In addition to duplexes, DNA can form unusual hybridized structures such as triplexes and quadruplexes. It has been proven by the groups of $\operatorname{Tan}^{37}$ and Mergny ${ }^{38}$ that the quadruplex-duplex transition could generate mechanical force. Their designs of G-quadruplex-based DNA nanomachines are simpler than that of duplex-based models. In their cases, only one G-rich strand is used to construct the main body of the machine, that is, an intramolecular G-quadruplex. The G-quadruplex state could be switched to the duplex form by adding DNA fuel. Through this transition, the distance between two ends of G-rich strand could be controlled. Hence, we may regard the G-quadruplex and duplex forms as closed and open states, respectively.

\section{DNA nanomachines controlled by non-DNA stimuli}

In principle, the above fuel-strands strategy could be applied to all strand-exchange reaction-powered DNA nanomachines, since, as we have mentioned, hybridization is the common feature of DNA. However, the main disadvantage is these reactions will result in cumulated duplex wastes. These useless duplexes may compete with surrounding nanomachines. And from the point of entropy flow, the accumulation of waste DNA will increase the entropy of the system and will eventually destroy the machine.

To avoid duplex wastes, non-DNA stimuli should also be choices for controlling motions. In fact, this approach has already been proposed in the construction of the first DNA-based nanomechanical device, ${ }^{23}$ in which case ethidium ions are used as intercalators to induce branch point migration in a tetramobile branched junction structure.

Simpler ions than ethidium have also been explored. Mao and Seeman have demonstrated a DNA machine based on a B-Z transition (Fig. 2). ${ }^{39}$ In the absence of $\mathrm{Co}\left(\mathrm{NH}_{3}\right)_{6}{ }^{3+}$ ion, sequence $(\mathrm{CG})_{10}$ forms normal right-handed B-DNA. This B-DNA can be transformed to left-handed Z-DNA upon the addition of a high concentration of $\mathrm{Co}\left(\mathrm{NH}_{3}\right)_{6}{ }^{3+}$ ion. The 


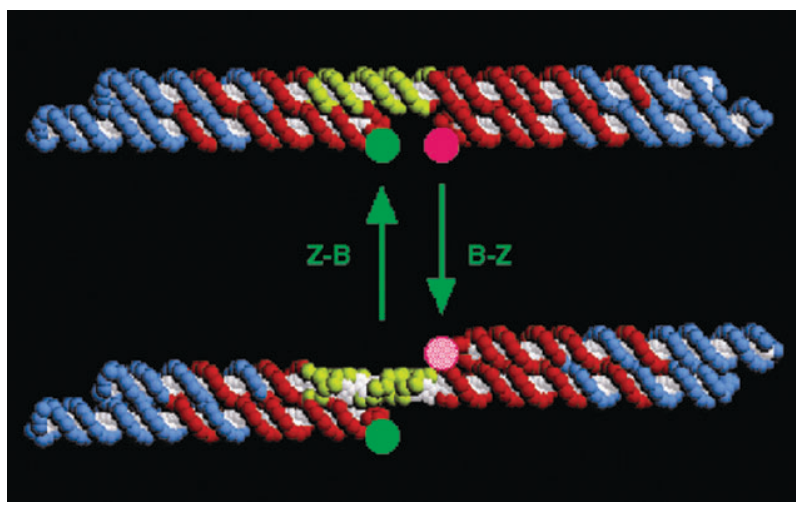

Fig. 2 An ion-triggered DNA rotary machine based on a B-Z conformational transition. The motor consists of two DNA double crossover (DX) molecules and at the centre of the connecting helix is a 20 -nucleotide region of proto-Z DNA shown in yellow. Fluorescent dyes fluorescein (green) and $\mathrm{Cy} 3$ (magenta) are attached to the free hairpins near the middle of the molecule. When the transition occurs, the two DX molecules change their relative positions and the separation of the dyes (reprinted with permission from ref. 39; copyright 1999, Nature Publishing Group).

whole transition will generate a rotary motion with about $2 \mathrm{~nm}$ displacement in space.

Based on the G-quadruplex structure, Fahlman et al. have constructed a nanopinching device which is sensitive to $\mathrm{Sr}^{2+}$ ion. ${ }^{40}$ This device's working mechanism is due to sequenced guanisines' ability of forming G-quadruplexes in the presence of metal ions. The addition of chelant EDTA to the solution will enable the removal of $\mathrm{Sr}^{2+}$ ion from G-quadruplex and break the pinched structure. Another ion-sensitive G-quadruplex nanomachine was developed by Sugimoto's group. ${ }^{41}$ Their machine is assembled from modified DNA strands, in which a coordination unit for divalent metal ions, $2,2^{\prime}$-bipyridine, is used to link two GGGG fragments. In the absence of $\mathrm{M}^{2+}$ ions, the modified sequence will self-assemble into an antiparallel G-quadruplex. Adding $\mathrm{Ni}^{2+}$ ion to the system will induce the rotation of the $2,2^{\prime}$-bipyridine unit and switch the structure to a parallel G-wire. Reverse reaction could be started by EDTA. Strictly speaking, this machine could not be regarded as an absolute DNA machine since its driving force is derived from the ion-sensitivity of the chemical unit.

For almost every chemical or biological system, the $\mathrm{pH}$ value is a very important factor. For some DNA structures, this is also true. For example, acidic $\mathrm{pH}$ favours the formation of the four-stranded C-rich i-motif structure and $\mathrm{C}^{+} \mathrm{GC}$ triplet because $\mathrm{C}$ base protonation $\left(\mathrm{C}^{+}\right)$will lead to extra hydrogen bonds. This concept has first been applied to DNA nanomachine construction by Liu and Balasubramanian. ${ }^{42}$ The system comprises a 21 mer strand $\mathbf{X}$ containing four CCC stretches and its partial complementary strand Y (Fig. 3). At slightly acidic $\mathrm{pH}$, half protonated $\mathrm{CCC}$ stretches will form intercalated $\mathrm{C}^{+} \mathrm{C}$ base pairs and induce $\mathbf{X}$ to fold into a compact i-motif structure, corresponding to the machine's closed state. Raising $\mathrm{pH}$ to slightly basic value will unfold $\mathbf{X}$ and form an extended duplex structure $\mathbf{X Y}$ (open state). Reversible switches between compact and extended states

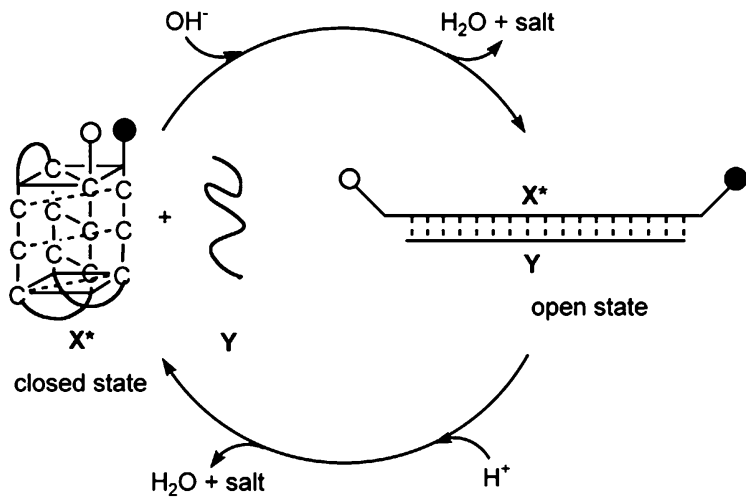

Fig. 3 An i-motif DNA-based nanomotor driven by $\mathrm{pH}$ change. Strand $\mathbf{X}$ contains four CCC stretches and can form a four-stranded i-motif structure in slightly acidic environment. With the increase of $\mathrm{pH}$, the i-motif structure will be destroyed and $\mathbf{X}^{\prime}$ s partial complementary strand $\mathbf{Y}$ will hybridize with $\mathbf{X}$ to form a duplex (reprinted with permission from ref. 42; copyright 2003, Wiley Interscience).

can be produced by changing the $\mathrm{pH}$ and both processes are completed in less than $5 \mathrm{~s}$. In total, the operations of this machine will result in a $5 \mathrm{~nm}$ linear movement and opening and closing forces both larger than $10 \mathrm{pN}$; the wastes are only salt and water from the neutralization reaction. The advantages of this proton-driven nanomachine are obvious: it is clear, quick, reliable and efficient. Similarly, the $\mathrm{pH}$-sensitive DNA triplex-duplex transitions have also been utilized to build DNA nanomachines by the groups of $\mathrm{Mao}^{43}$ and Zuccheri. $^{44}$

Another approach to stimulate DNA structural transformation is changing the temperature. Although all nucleic acid structures are sensitive to temperature change, Sugiyama's work demonstrated that DNA and RNA may have inverse responses to thermal stimuli and therefore produce opposite rotations. ${ }^{45}$ On the other hand, Isambert et al. concentrated on controlling the folding kinetics of a DNA nanoswitch by modulating its annealing cooling rate. ${ }^{46}$ By fast cooling, a metastable conformation is favoured kinetically.

A protein-driven DNA nanomechanical device has been proposed by Seeman's group. ${ }^{47}$ In the report, E. coli integration host factor (IHF) has the ability to distort the device by recognizing and binding specific DNA sequences in the device. This device was suggested to be effective in measuring the interaction between protein and DNA.

\section{Unidirectional motions}

The machines already described above have fixed links between their primary elements. The motions of those DNA machines are all fundamentally intramolecular. A challenge arises as to mimic biological molecular motors ${ }^{21,22}$ such as myosins, kinesins and dyneins that can perform unidirectional motions on external tracks. One of the most attractive features of this kind of motion is its ability to transport substances at the nano- or micro-scale.

The simplest kind of unidirectional motion is linear walking. This has now been achieved by DNA-based devices in a few instances. In 2004, Seeman's group reported a biped DNA 


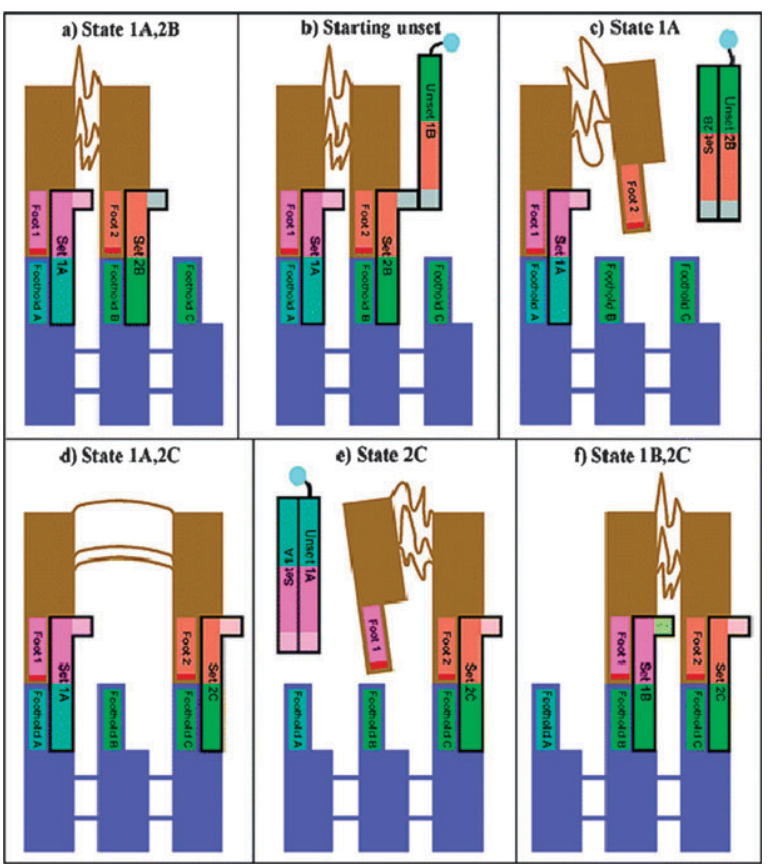

Fig. 4 A DNA biped walker. The track is drawn in blue and the walker is drawn in brown. Matching colours indicate complementary sequences between strands. The walker could walk on the track step by step in a certain direction controlled by set and unset strands (reprinted with permission from ref. 48; copyright 2004, American Chemical Society).

walker machine ${ }^{48}$ whose working mechanism is shown in Fig. 4. Their device consists of two parts: a three-step track and a biped walker. The track itself is in fact a triple crossover (TX) molecule ${ }^{49}$ with three single-stranded overhangs which serve as "footholds". The biped region has two duplex "legs" and on the end of each leg there is a singlestranded "foot". Three additional single-stranded linkers between the two legs make the biped walker flexible. A foot attaches to a foothold when a "set" strand complementary to both is added. The biped region will walk on the track in a certain direction if specific set and unset strands are added sequentially.

Shin and Pierce have proposed another simple approach for a DNA walker. ${ }^{50}$ Their device has also two main components: a walker and a track which are both in duplex forms. The walker is a partially complementary duplex with two singlestranded overhangs as legs. The track consists of six oligonucleotides and has four protruding single-stranded branches. With the similar walking principle to Seeman's device, the walker can move on the track by set and unset strands.

The above two DNA walkers, although their structures are different, have similar working mechanisms. One of their common features is that the walking steps in a certain direction is limited to the number of footholds or branches on the track. We could imagine if the track is a circle rather than a line, the walker may always move unidirectionally. This kind of motion has been realized in a DNA nanogear model by Mao's group..$^{51}$ The gear system has two DNA duplex circles. Each circle contains four oligonucleotides and three singlestranded overhangs as "teeth". These two circles may roll against each other driven by the "fuel-strands" mechanism which was also applied in the above two DNA walkers.

\section{Evolution of kinetics and driven modes}

One of the critical issues involved in all kinds of nanomachines is how to control their motions precisely. In natural systems, the sophisticated motions of protein-based nanomotors are the results of complicated biological cooperations, and natural evolution makes these machines work at their best. For most DNA-based nanomachines, motions are generated from DNA hybridizations. So the question now should be how to evolve the kinetics and efficiency of the hybridizations in the DNA nanomachines. Basically, many factors such as the machine's structure, environment, fuel and control mode will have certain impacts.

\section{Evolution of hybridization kinetics of "fuel-strands"}

The "Fuel-strands" strategy was first established in DNA tweezer work by Yurke et al. ${ }^{30}$ In that work, both opening and closing of the machine are controlled by the added fuel DNA. The fuel strand will at first hybridize with a dangling end; then displace an entire strand through branch migration. This strand-exchange reaction is spontaneous and fast so the kinetics of both opening and closing processes can not be controlled. As a result, free fuel and anti-fuel strands can not exist in the same system and they must be added step by step.

With the purpose of kinetic control of the DNA hybridization process, Turberfield et al. proposed an ingenious strategy of using a partially complementary protective strand to pre-hybridize with the fuel strand (Fig. 5A). ${ }^{52}$ The particular character of this pre-hybrid is its internal loop structure. The authors have proved that this metastable loop structure is effective in inhibiting the hybridization between the protected fuel strand and free anti-fuel strand. This strategy is exciting because the fuel and anti-fuel strands now can coexist in the same system, which means that all DNA strands, including machine and fuels, could be mixed together in a batch to start the motion. In other words, this creates the opportunity to design autonomous DNA-fuelled nanomachines. In their work, the machine itself has been regarded as a "catalyst" whose function is to accelerate fuel and anti-fuel hybridization. In the first step, protected strand can be displaced by the catalyst strand to open the loop. In the next step, anti-fuel will displace catalyst. Finally, the reaction releases waste product (fuel/anti-fuel duplex and protected strand) and the catalyst returns to the random coil state. This three-step reaction will repeat as long as fuels are available. The loop structure has been studied in detail in another work to clarify its function and interactions with other strands. ${ }^{53}$

In an extended work, ${ }^{54}$ Seelig and Winfree et al. improved the catalyst system by more than two orders of magnitude. This was achieved by using two protective strands for both fuel and anti-fuel strands and a "kissing loop" is necessary for their system. The concept of "catalyst" has also been used in works about speeding up a G-quadruplex nanomachine ${ }^{55}$ and building DNA-based cascaded circuits. ${ }^{56}$

Recently, Pierce et al. has accomplished a unidirectional hybridization driven polymerization motor (Fig. 5B) ${ }^{57}$ In 


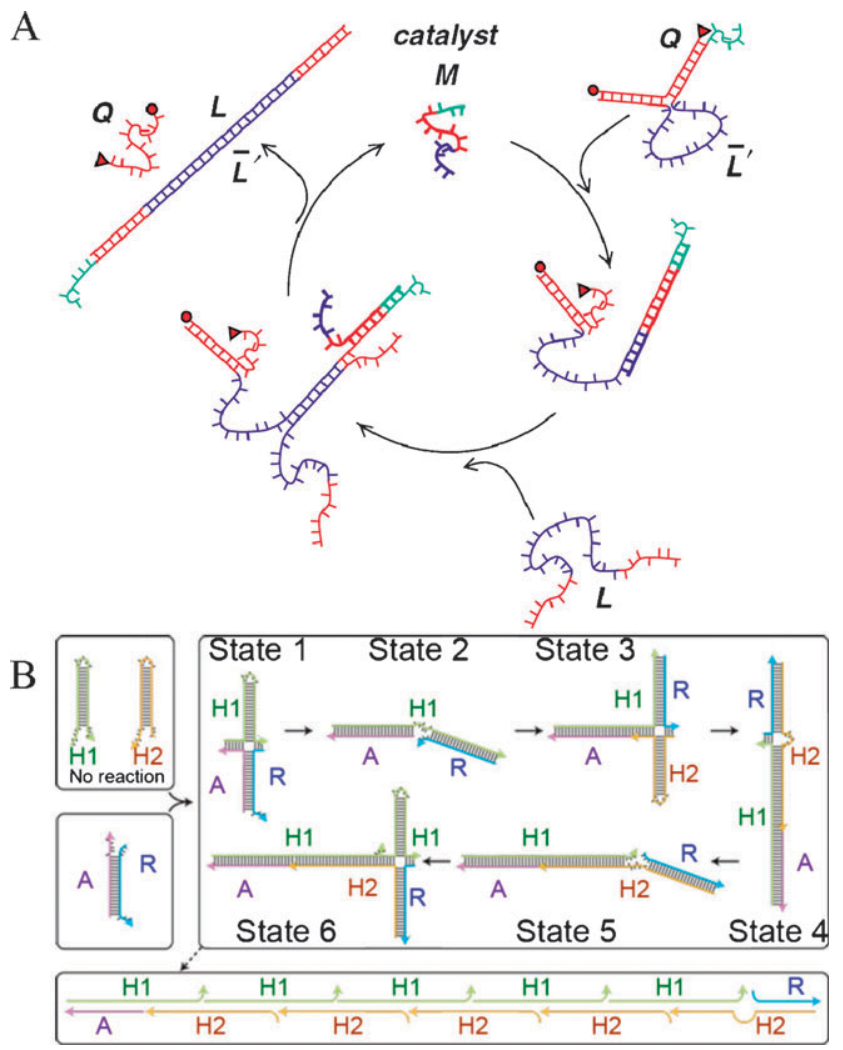

Fig. 5 Autonomous DNA nanomachines. (A) DNA "catalyst" system. In this design, machine (catalyst strand) undergoes three continuous steps of motions: hybridization, dehybridization and release. The whole process will repeat unless all fuel strands have been used up (reprinted with permission from ref. 52; copyright 2003, American Physical Society). (B) An autonomous polymerization motor. The metastable fuel hairpins (H1 and H2) do not interact in the absence of the AR complex. Upon mixing, $\mathbf{H 1}$ binds to the sticky ends of AR (State 1), initiating a four-way branch migration in which $\mathbf{R}$ is passed from $\mathbf{A}$ to $\mathbf{H 1}$ (State 2). $\mathbf{H} \mathbf{2}$ then binds to the newly exposed sticky ends (State 3) and $\mathbf{R}$ is passed from $\mathbf{H 1}$ to $\mathbf{H 2}$ (State 4). In this manner, the $\mathbf{R}$ strand is passed back and forth between $\mathbf{H} \mathbf{1}$ and $\mathbf{H} \mathbf{2}$ hairpins at the living end of the growing polymer, moving away from the A strand (reprinted with permission from ref. 57; copyright 2007, Nature Publishing Group).

their design, two metastable hairpin molecules are used as fuels and the initial machine is a duplex. By mixing the machine and fuels, the duplex will be broken and strand $\mathbf{A}$ binds to $\mathbf{H 1}$ fuel (State 1), initiating a four-way branch migration in which $\mathbf{R}$ is passed from $\mathbf{A}$ to $\mathbf{H 1}$ (State 2). $\mathbf{H 2}$ then binds to the newly exposed sticky ends (State 3 ) and $\mathbf{R}-\mathbf{H 1}$ duplex is displaced by $\mathbf{R}-\mathbf{H} 2$ duplex. The $\mathbf{R}$ strand will always move away from the A strand autonomously in the presence of fuels. The motion of this system mimics bacterial pathogens. ${ }^{58}$ It is intriguing that no preformed track is required and the growing duplex may provide a track for other DNA nanomachines.

\section{Enzyme-assisted DNA nanomachines}

Enzymes are natural catalysts for many DNA-based reactions. It is possible to use enzymatic reactions to control the structure of DNA and make DNA mechanical devices.

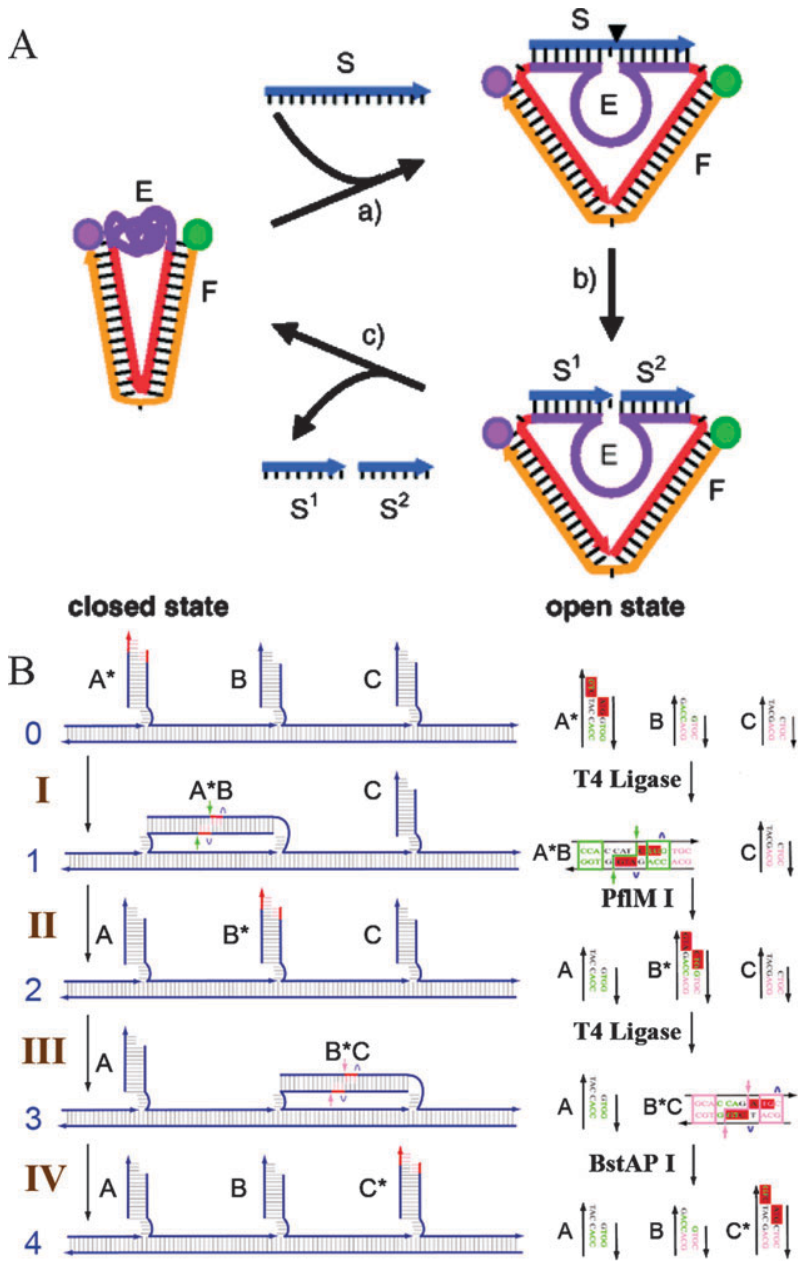

Fig. 6 Enzyme-assisted DNA nanomachines. (A) An autonomous DNA nanoswitch powered by a DNA enzyme. The $\mathbf{E}$ strand contains an RNA-cleaving DNA enzyme and its substrate is an $\mathbf{S}$ strand. The cleavage of $\mathbf{S}$ will induce the closing of the machine. $\mathbf{E}$ will bind with another $\mathbf{S}$ strand and open the machine again in the next step (reprinted with permission from ref. 59; copyright 2004; Wiley Interscience). (B) An enzyme-controlled DNA walker. The track consists of three evenly spaced duplex-DNA anchorages, A, B and $\mathbf{C}$. A special part which is drawn in red is the walker. Initially, $\mathbf{A}^{*}$ which carries the walker part will be ligated to $\mathbf{B}$ and then the duplex will be cut by endonuclease. The walker part has thus been transported to $\mathbf{B}$. In a similar manner, the walker could be further transported to $\mathbf{C}$ (reprinted with permission from ref. 62; copyright 2004; Wiley Interscience).

The first enzyme-assisted DNA nanomachine was reported by Mao's group in an autonomous DNA motor. ${ }^{59}$ Their machine consists of two strands ( $\mathbf{E}$ and $\mathbf{F})$ shown in Fig. 6(a). The E strand contains an RNA-cleaving DNA enzyme. The $\mathbf{S}$ strand is a DNA-RNA chimera which is the substrate of the enzyme of $\mathbf{E}$. Upon binding, the machine will be opened by the SE duplex. The DNA enzyme $\mathbf{E}$ cleaves its substrate $\mathbf{S}$ into two short fragments which have a lower affinity for the $\mathbf{E}$ strand than the intact substrate and will, therefore, dissociate from the machine. Its open and closed states transitions could be switched autonomously by the enzymatic reaction. The machine could be temporarily stopped by adding brakes. ${ }^{60}$ Recently Bishop et al. have 
developed a method for improving its efficiency by using the enzyme ribonuclease $\mathrm{H}$ to selectively digest waste. ${ }^{61}$

The enzyme-assisted method could be extended to make DNA walkers. Three different approaches have been reported up to now. One of these is controlled by ligase and endonuclease as studied by Yin et al. (Fig. 6(b)). ${ }^{62}$ This device also contains two components like other DNA walkers: the track and the walker. The track is a long duplex with three short duplex anchorages. The walker part is a six-nucleotide fragment which is always covalently linked to anchorages. Initially, the walker is on anchorage A. A step of this machine could be divided into two half steps: firstly, the walker's sticky end will complement with anchorage $\mathbf{B}$ and be ligated to $\mathbf{B}$ by T4 ligase; endonuclease PflM I then recognizes the newly formed reorganization site and cuts the strand. As a model and regardless of the length of the track, this machine could walk autonomously and unidirectionally along a track.

The other two examples of enzymatic DNA walkers are similar in walking mechanisms, but with different enzymatic principles. The work done by Mao's group is based on the DNA enzyme. ${ }^{63}$ The track in their work is a long duplex with single-stranded DNA-RNA chimera protrudings as anchorages. A DNA enzyme-contained sequence is used as the walker. When the walker binds to a anchorage, it will cut the anchorage and move to the next one. The machines in this case are also autonomous and unidirectional. A striking feature is its ability to move infinitely if anchorages are available. In another approach, ${ }^{64}$ Bath et al. employed restriction endonuclease to cut the anchorages the make the walker move, which will generate the same result as Mao's design.

\section{Evolution of kinetics by changing environment}

Environmental factors play an important role in the movements of DNA nanomachines. For example, a change in $\mathrm{pH}$ in solution will induce the motions of i-motif and triplex based DNA nanomotors. The key parts of these proton-driven nanomachines are $\mathrm{pH}$-sensitive DNA segments (C-rich strands) which will be in folded and unfolded states, respectively, under different $\mathrm{pH}$ values. It is interesting to speculate that if the $\mathrm{pH}$ changing in solution could be controlled by a coupled system, the kinetics of proton-driven DNA nanomachines would be managed. In 2005, Liedl and Simmel reported such an approach of controlling an i-motif DNA motor ${ }^{65}$ by a chemical oscillator. As shown in Fig. 7, strand $\mathbf{M}$ ( $\mathbf{M}$ has the same sequence, except end modifications, with $\mathbf{X}$ in Fig. 3) would undergo conformational switches between fourstranded i-motif and single-stranded random coil structures reversibly and periodically, driven by a $\mathrm{pH}$ oscillator in a semibatch reactor. The $\mathrm{pH}$ oscillator in this case is a variant of the Landolt reaction. ${ }^{66}$ The alternating oxidation of sulfite and thiosulfate by iodate is accompanied by a periodic production or consumption of protons. This oscillation reaction varies the $\mathrm{pH}$ value between 5 and 7 periodically and then leads to DNA conformational switches. A feed solution for the oscillator is pumped slowly and continuously into the system, which also brings a disadvantage as the oscillator will die out after several cycles as a result of the continuous decrease in reactant concentrations. Anyhow, this design of coupling $\mathrm{pH}$ oscillator

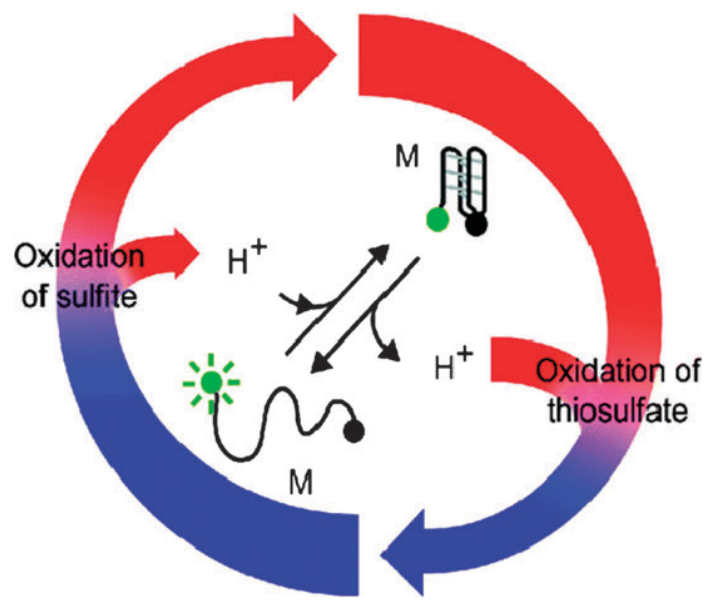

Fig. 7 DNA conformational switches between the i-motif and ssDNA driven by a chemical oscillator. In one-half of the reaction cycle, protons produced during the oxidation of sulfite induce the formation of the i-motif. In the other half of the reaction cycle, the oxidation of thiosulfate consumes protons and leads to ssDNA (reprinted with permission from ref. 65; copyright 2005, American Chemical Society).

has shed light on making autonomous proton-driven DNA nanomachines.

For DNA nanomachines powered by strand-exchange reaction, the output and frame strength of the machines depend on the stability of DNA hybrids, while the quick response relies on hybridization speed. It is difficult to satisfy both requirements simultaneously because usually they will contradict each other. Maruyama' group developed a cationic copolymer-assisted strategy to solve such a problem using G-quadruplex and DNA tweezer nanomachines as models. ${ }^{67,68}$ The strategy is partially an extended work of their previous studies on interactions between cationic comb-type copolymers and triplex ${ }^{69}$ and duplex ${ }^{70}$ DNA. In those studies, they found poly(L-lysine)-graft-dextran (PLL-g-Dex) copolymers have special functions of accelerating strand-exchange reaction while stabilizing DNA hybridization. Similarly, the addition of PLL-g-Dex to the G-quadruplex nanomachine system will increase opening and closing rates by $70-$ and 40 -fold, respectively, while boosting the motion efficiency. For DNA tweezers, the performance could also be improved by PLL-g-Dex copolymers.

\section{Non-contact control modes}

The development of non-contact control modes, such as lightand electricity-control, for stimulating DNA nanomachines is a critical challenge. Non-contact systems offer distinct advantages to contact modes controlled DNA nanomachines in terms of simplifying the experiment by freeing our hands from adding fuels manually and improving the efficiency and precision of the machine by eliminating manual errors, making it possible to perform complicated motions and communicate with other nano-objects. Although light- and electricitycontrolled chemical nanomachines have already been achieved, ${ }^{17-20}$ it is not easy to extend these strategies to DNA-based machines since natural DNA is insensitive to those stimuli. Basically, in terms of non-contact control of 
DNA nanomachines, there are only two routes we can evisage: the first route is using artificial DNA strands which contain light or electrical responsive modifications; the second route is switching the environment by external non-contact stimuli. These two routes have both been realized recently.

Asanuma's group reported light-controlled DNA tweezers with covalently tethered azobenzene moieties on the fuel strand. ${ }^{71}$ Since the azobenzene group is sensitive to light irradiation and its photoresponsive trans- and cis-isomers have different stacking abilities with DNA base-pairs, the stability of azobenzene-containing DNA duplexes and triplexes could be regulated by UV and visible light. They have proved in their previous work that the planar trans-azobenzene could intercalate between adjacent base-pairs and stabilize the duplex or triplex structure by stacking interactions, whereas the nonplanar cis-azobenzene would destabilize it by steric hindrance. In their design of DNA tweezers, 12 azobenzene groups have been incorporated into the fuel strand. Under the alternate irradiation of UV and visible light, azobenzene moieties are in the cis- and trans-configurations, respectively. Therefore, the stability of DNA duplex formed by the tweezer overhangs and fuel strand could be switched. The tweezers will open in UV light and close in visible light.

The above route needs specific modifications of DNA strands, which brings difficulty in DNA synthesis. For natural DNA, the second route mentioned above may be more effective. In 2007, our lab first reported an approach of controlling DNA conformational switch between the i-motif and ssDNA structures by light (Fig. 8). ${ }^{72} \mathrm{MGCB}$ is a photochromic molecule which could generate a hydroxyl ion under UV light with the reverse process occurring in the dark. By turning on/off the UV light, MGCB molecules produce cycles of $\mathrm{pH}$ jumps in solution. Since the DNA conformational switch in our system is $\mathrm{pH}$-sensitive, the coupling of a lightinduced $\mathrm{pH}$ jump system will realize DNA conformational

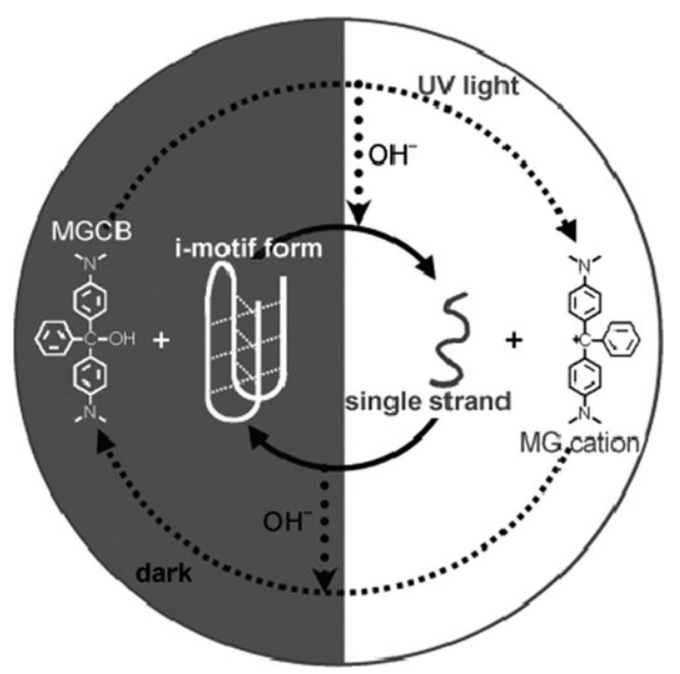

Fig. 8 DNA conformational switches between i-motif and ssDNA controlled by light irradiation. Inner cycle: the DNA conformational switch between the i-motif and ssDNA. Outer cycle: the light-induced $\mathrm{pH}$ jump. The conformational switch of DNA $\mathbf{X}$ is associated with the on and off phases of UV light (reprinted with permission from ref. 72; copyright, 2007, Wiley Interscience). switches controlled by light. An advantage of this strategy is that we do not need any modifications on DNA. Both ours and Asanuma's work used light as control signals and so do not produce wastes.

\section{Functional evolution of DNA nanomachines}

What complicated work can DNA nanomachines do is a very interesting question. Basically, there are several requirements for DNA nanomachines to do practical work: (1) the machine's motion must be stable and powerful; (2) the operation should be simple and clean; (3) the machine should be coupled to the object which is going to be driven.

\section{Constructing switchable surface}

Although a single DNA nanomotor could only generate a force at the $\mathrm{pN}$ level, the possibilities for the cooperative motions of many such motors, is clearly of importance. An approach to test this cooperative effect is by immobilizing DNA nanomotors on a surface.

Liu and Zhou et al. reported the immobilization of i-motif DNA nanomotors onto defined locations of a microstructured surface to form a microarray. ${ }^{73}$ Based on the conventional thiol-gold interaction, the authors coupled thiol-modified DNA motors to an Au surface, while the other end of each DNA motor has a fluorophore modification. Then patterns have been constructed on the above DNA monolayer. The results demonstrated that the motor function was maintained on the surface and an on-off optical switch, which is the result of the cooperative work from numerous motors, could be produced by changing $\mathrm{pH}$. The working mechanism is that under different $\mathrm{pH}$ values, the distance between the fluorophore and Au surface could be switched, leading to different FRET efficiencies. In a similar work, Simmel et al. utilized their improved $\mathrm{pH}$ oscillator system to control the $\mathrm{pH}$ switch. ${ }^{74}$ This work realized the autonomous switching of surface optical signals for many cycles. The ability of controlled immobilization of DNA motors on a defined surface is an important first step towards the construction of complicated nanodevices.

Based on the above work, it is possible to switch the surface function by DNA nanomotors in response to stimuli. Fig. 9 shows the effort of switching surface wettability by three-state i-motif DNA nanomachines. ${ }^{75}$ The DNA nanomotors were coupled to a gold surface through thiol-Au bonds and a hydrophobic Bodipy-type fluorophore was attached on the other end of the DNA strand. At low pH (state I), DNA motors are in the closed states and hydrophilic phosphate backbones of DNA strands are exposed, leading to a hydrophilic surface. By raising the $\mathrm{pH}$ (state II), DNA motors will adopt ssDNA forms and the Bodipy groups will no longer be concealed. Therefore the surface will be switched to hydrophobic wettability. The state II is not stable for long time since it is a loosely disordered state. The addition of complementary strands of DNA motors could help DNA adopt rigid duplex conformations and make the monolayer be closed packed (state III). At this state the hydrophobic behaviour is stable. It is interesting to note that a rough surface could enhance surface wettability, either hydrophilicity or hydrophobicity. ${ }^{76}$ 


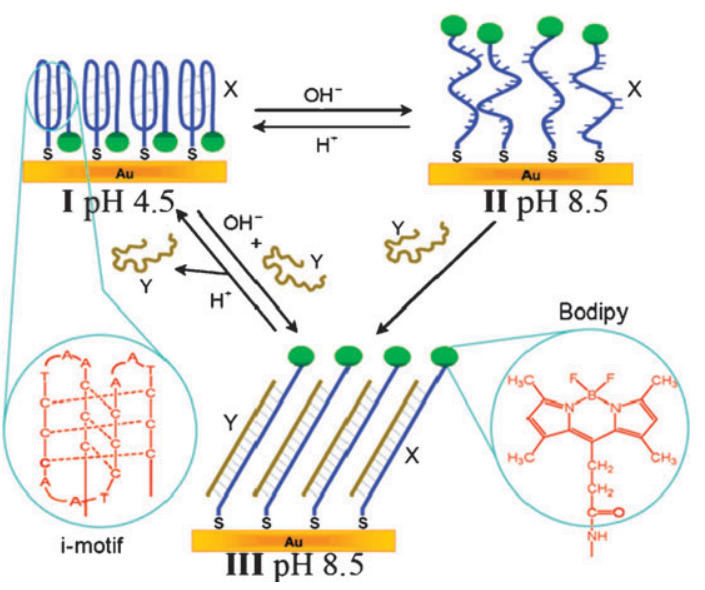

Fig. 9 DNA nanomachine-controlled surface wettability switch. At low $\mathrm{pH}$, the DNA adopts an i-motif conformation (state I). Raising the $\mathrm{pH}$ destabilizes the i-motif to produce a stretched single-stranded state (state II) or a duplex structure (state III, when a complementary strand is present). Lowering the $\mathrm{pH}$ induces a reverse conversion process from state II or III to state I (reprinted with permission from ref. 75; copyright 2007, Wiley Interscience).

In our system, switches between superhydrophilic and superhydrophobic wettabilities could be produced by DNA nanomachines on rough substrates.

\section{Directing chemical reactions}

DNA-templated chemical synthesis ${ }^{77-79}$ is a strategy that could select targets and increase the effective molarity of DNA-linked reactants by sequence-specific DNA hybridization. The utilization of DNA nanomachines could exert remarkable controllability to trigger the synthesis process.

Based on pH-driven triplex-duplex DNA nanodevices, Chen and Mao realized switching chemical reactions between two identical reagents. ${ }^{80}$ In response to the change of solution $\mathrm{pH}$, the DNA device changes its conformation and repositions chemical reagents that are conjugated with DNA strands. As a result, chemical reactions are reprogrammed.

Other than most DNA nanomotors which generate open-closed type motions, the PX-JX $\mathrm{X}_{2}$ machine ${ }^{34}$ developed by Yan and Seeman could exert robust rotations between its two topological states $\mathrm{PX}$ and $\mathrm{JX}_{2}$. By incorporating two $\mathrm{PX}-\mathrm{JX}_{2}$ machines in succession, its motions will produce four different combinations: PX1-PX2, PX1-JX 2 , JX $21-\mathrm{PX} 2$ and $\mathrm{JX}_{2} 1-\mathrm{JX}_{2} 2$. In an attractive work carried out by Liao and Seeman, ${ }^{81}$ they translated DNA signals of such a twosuccessive $\mathrm{PX}-\mathrm{JX}_{2}$ machine into polymer assembly instructions and obtained four ligated products. Their design mimics the translational capabilities of the ribosome. In response to a DNA signal (set strands for a specific combination of the machine), the machine drives substrates (DNA motifs for assembling polymer) to form a specific linear array; and aligns a series of DNA strands (could be regarded as polymer) in specific positions; these strands are then fused together in a specific order. The products are DNA oligonucleotides of a defined sequence. In theory, if $N$ single $\mathbf{P X}-\mathrm{JX}_{2}$ machines are present, the number of combinations and assembled products will be as large as $2^{N}$. This DNA machine-based translation
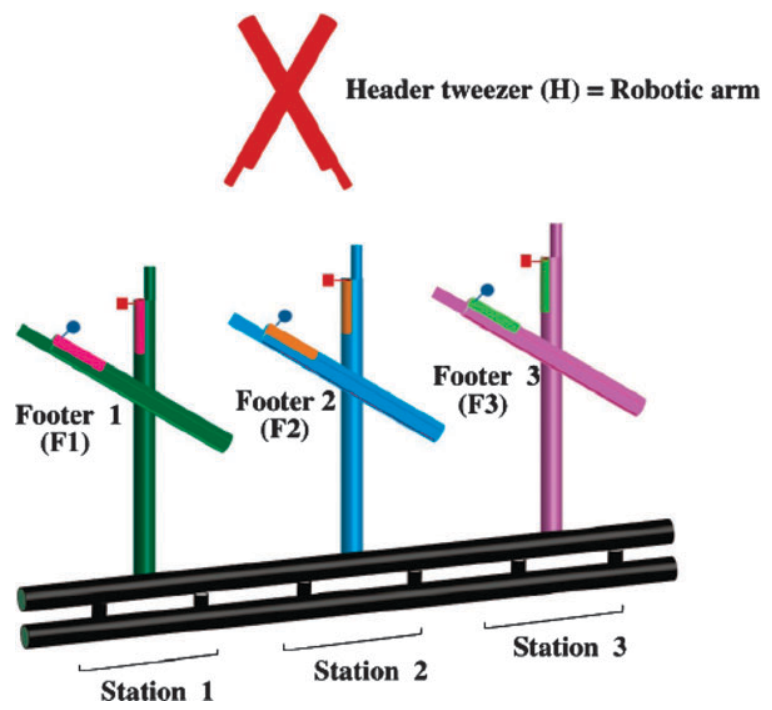

Fig. 10 Addressable DNA tweezers for templated coupling reactions. Three footers, F1, F2 and F3, link to the track containing a linear array of DNA double crossover motifs. The red and blue dots represent $-\mathrm{NH}_{2}$ and $-\mathrm{COOH}$ groups, respectively. By adding of a specific pair of set strands, the header $(\mathbf{H})$ can go to any footer on the track, facilitating the formation of three specific amide bond coupled products (reprinted with permission from ref. 82; copyright, 2006, American Chemical Society).

system has promising applications in directed assembly, molecular computing, and encryption.

Programmable chemical reactions could also be performed on an addressable DNA tweezer array. ${ }^{82}$ In a report from Yan and co-workers (Fig. 10), three tweezers, each bearing two coupling reactants, are self-assembled on a linear DNA track. A fourth tweezer floating freely in solution can be bound to any one of the tweezers and close them by the addition of a unique pair of fuel strands. The coupling reactions occur when the tweezers are closed, and this can be controlled sequentially from one tweezer to the next.

\section{Driving objects}

For most DNA nanomotors, the force comes from the free energy released by the DNA hybridization process. Actually, even before the invention of the first DNA-based nanomechanical device, ${ }^{23}$ the concept that DNA hybridization could be employed to drive nano-objects such as gold nanoparticles was already been proved by pioneering work of Mirkin $^{83}$ and Alivisatos. ${ }^{84}$ Niemeyer et al. realized reversible switching of DNA-gold nanoparticle assembly by using fuel-strands. ${ }^{85}$ DNA triplex-based gold nanoparticle reversible assembly has been achieved by a proton-fuelled strategy. ${ }^{86}$ More recently, our ${ }^{87}$ and Yan's ${ }^{88}$ groups have published our approaches of making i-motif DNA nanomotors controlling gold nanoparticle assembly. Also in work based on an i-motif DNA motor, Li et al. demonstrated that its power can been used to break certain forms of Watson-Crick interactions. ${ }^{89}$

We have demonstrated that the immobilization of numerous DNA nanomotors on a substrate will generate a cooperative effect which is able to change the surface property. ${ }^{75}$ Further, the force generated from these immobilized nanomotors, has 


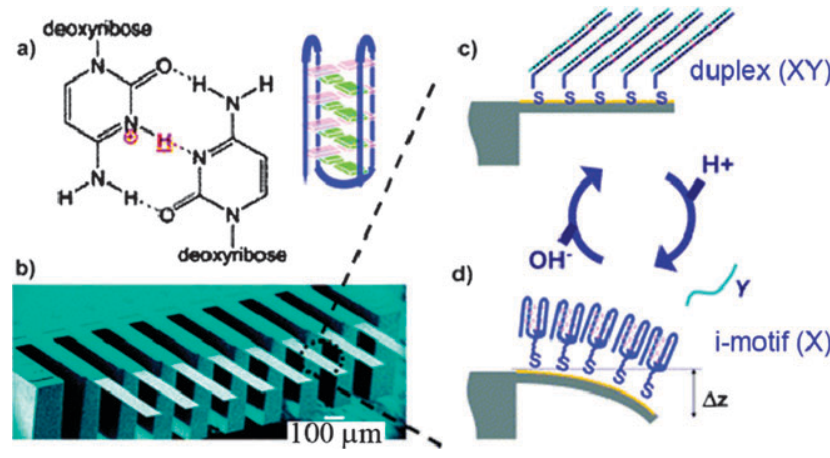

Fig. 11 Bending metallic microcantilever by DNA nanomachines. At high $\mathrm{pH}$ the hybridization of surface-tethered $\mathbf{X}$ to strand $\mathbf{Y}$ in solution forms the duplex structure. At low $\mathrm{pH}, \mathbf{X}$ forms the self-folded i-motif and induces repulsive in-plane surface forces (compressive surface stress) which causes the cantilever to bend downward (reprinted with permission from ref. 90; copyright 2005, American Chemical Society).

been proved to be strong enough to drive objects much larger than nanosized. As shown in Fig. 11, McKendry et al. have shown it is possible to convert the force to bend microcantilever arrays. ${ }^{90}$ Open-state i-motif DNA motors (in duplex) were assembled on one side of a cantilever. By decreasing the $\mathrm{pH}$ value the DNA motors will adopt i-motif forms. Upon formation of i-motif structures, DNA motors will exert repulsive in-plane surface forces (compressive surface stress) which cause the cantilever to bend downward. The magnitude of this surface stress has been measured as around $32 \mathrm{mN} \mathrm{m}^{-1}$. The bending process is highly reversible by switching DNA motors. The origin of this surface stress has been attributed mainly to electrostatic repulsions. The authors suggested that both inter- and intra-molecular repulsions of the fourstranded i-motif structure is higher than for the duplex form, and therefore the compressive stress will induce the bending of the cantilever to increase the available surface area. This work first certified that the cooperative effect of DNA nanomotors could generate a dramatic force large enough to drive even a macroscopic object. The cooperation-based approach should be applicable to other DNA nanomachines to amplify their working abilities to the macroscale.

The evolution of the PX-JX $\mathbf{X}_{2}$ machine has resulted in a DNA nanorobot. ${ }^{91}$ As shown in Fig. 12, a cassette system contains a $\mathrm{PX}-\mathrm{JX}_{2}$ machine, an attachment site, and a report hairpin, and many such cassettes have been incorporated into 2D DNA crystalline substrates to form arrays. Switching $\mathrm{PX}-\mathrm{JX}_{2}$ nanomachine states by set strands will induce the rotation of a reporter hairpin. Since the 2D DNA lattice serves as a fixed frame of reference, the rotations of reporters will generate measurable directional displacements on the DNA substrate. As monitored by AFM, the rotations of the hairpins relative to the 2D DNA lattice could be easily visualized. The appealing feature of this work is the realization of integrating DNA nanomachines with DNA assembled nanopatterns. It is expected that the DNA reporters could do practical work to mimic robot arms.

A unique work noted in the final part of this section is a DNA supercoiling based switching of DNA-nanoparticle networks. ${ }^{92}$ Streptavidin (STV) particles have been used to link

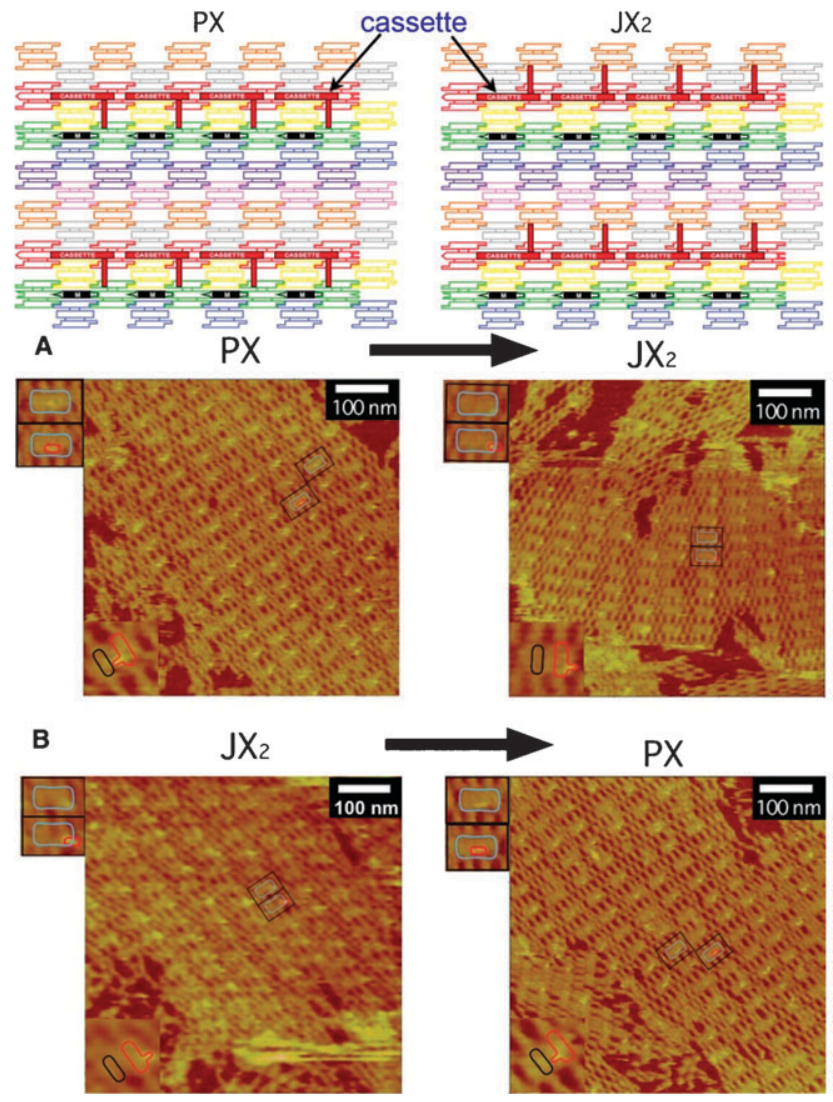

Fig. 12 DNA nanomachine-based nanorobots. Top: cartoons show that the array is formed by eight triple crossover tiles. The cassette and reporter helix are shown as solid red components and the black parts are markers. Bottom: AFM images show that the positions of the reporter hairpin (in red circle) in the $\mathrm{PX}$ and $\mathrm{JX}_{2}$ states are different (reprinted with permission from ref. 91; copyright 2006, AAAS).

DNA strands to form dsDNA-STV networks. Upon raising the magnesium concentration in the system, DNA condensation (thickening and shortening) could be observed which is probably due to a supercoiling motion of the DNA fragments.

\section{As sensors}

Sequence-specific DNA detection is very important in various biomedical applications. The recent work of Crain's group has presented a new method to discriminate single-base mismatches based on DNA nanoswitches. ${ }^{93,94}$ In their design, the probe and target DNA will form a switchable four-way Holliday junction. A remarkable characteristic of this complex is its ability to switch in response to stimuli such as divalent ions. It has been found that changes in the switching characteristics of such a device can be used to differentiate various targets. A 30-fold discrimination between singlenucleotide mismatches in a DNA oligonucleotide could be obtained. This method may be useful in single nucleotide polymorphism (SNP) discrimination.

Willner's group has contributed much work in DNA machine based sensors in recent years. Fig. 13 shows their work for detecting M13 phage ssDNA. ${ }^{95}$ In the presence of target DNA strands, the hairpin will be opened and then polymerization will be triggered. However, the polymerized 

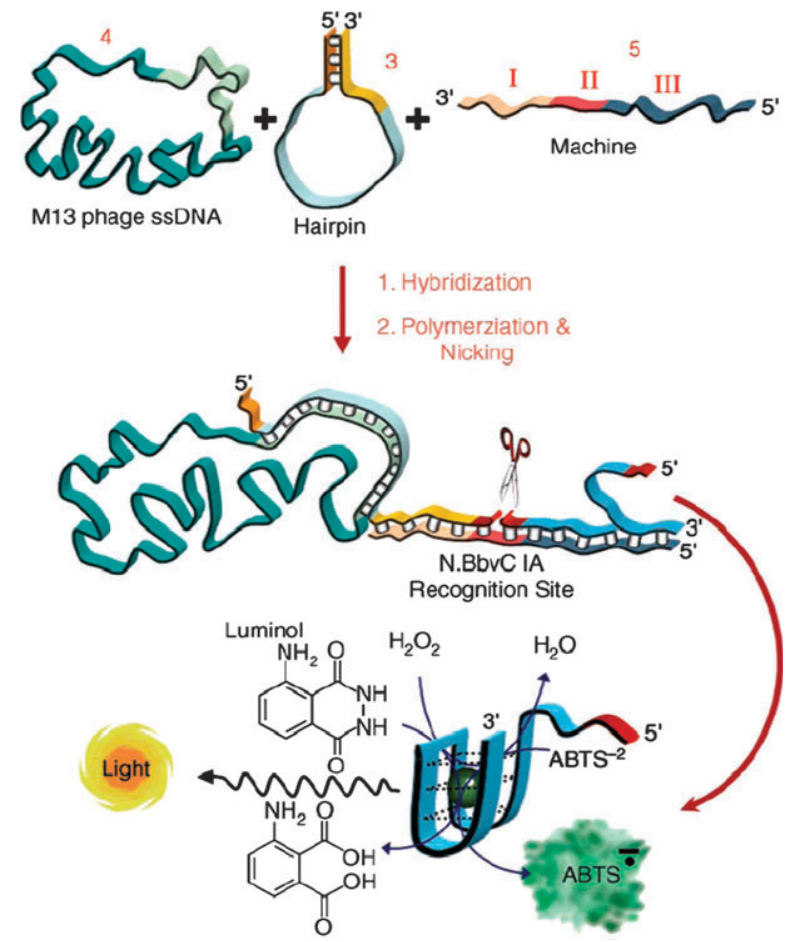

Fig. 13 Detecting ssDNA targets by DNA nanomachine. M13 phage ssDNA will hybridize specifically to a hairpin strand and then produce a large amount of G-quadruplex structures. The intercalation of hemin molecules to the G-quadruplex will catalyze an oxidation reaction which will generate chemiluminescence (reprinted with permission from ref. 95; copyright 2006, Wiley Interscience).

duplex domain contains a N.BbvC IA recognition site which will cause the nicking (scission) of the replicated single strand and the resultant sequence will fold into a G-quadruplex with an intercalated hemin molecule. The complex mimics peroxidase activity and catalyzes an oxidation reaction. The generation of chemiluminescence from this reaction could be detected as an output signal. The obtained G-quadruplex sequences could also be designed to induce nanoparticle aggregation. ${ }^{96}$ Other work by this group includes constructing sensors for detecting cocaine ${ }^{97}$ and mercury ions. ${ }^{98}$

\section{Performing controllable release}

Controllable collection/release of molecules or nanomaterials is a critical issue for materials science, pharmaceutics, biomedical applications, and also for constructing hierarchical nanodevices. The feature of generating a nanomechanical output makes DNA nanomachines an ideal tool to trigger such nanoscale processes. The challenge is the conversion of mechanical force to signals for releasing targets. Up to now, two strategies have been explored.

The first strategy is the direct utilization of the DNA nanomachines' force to change the volume of a nanoscale container. Such a controllable DNA nanocontainer system has been developed by our group in 2007 (Fig. 14(a)). ${ }^{99}$ The device was implemented with the success of immobilization of DNA nanomotors on a surface. ${ }^{73}$ The most distinctive characteristic
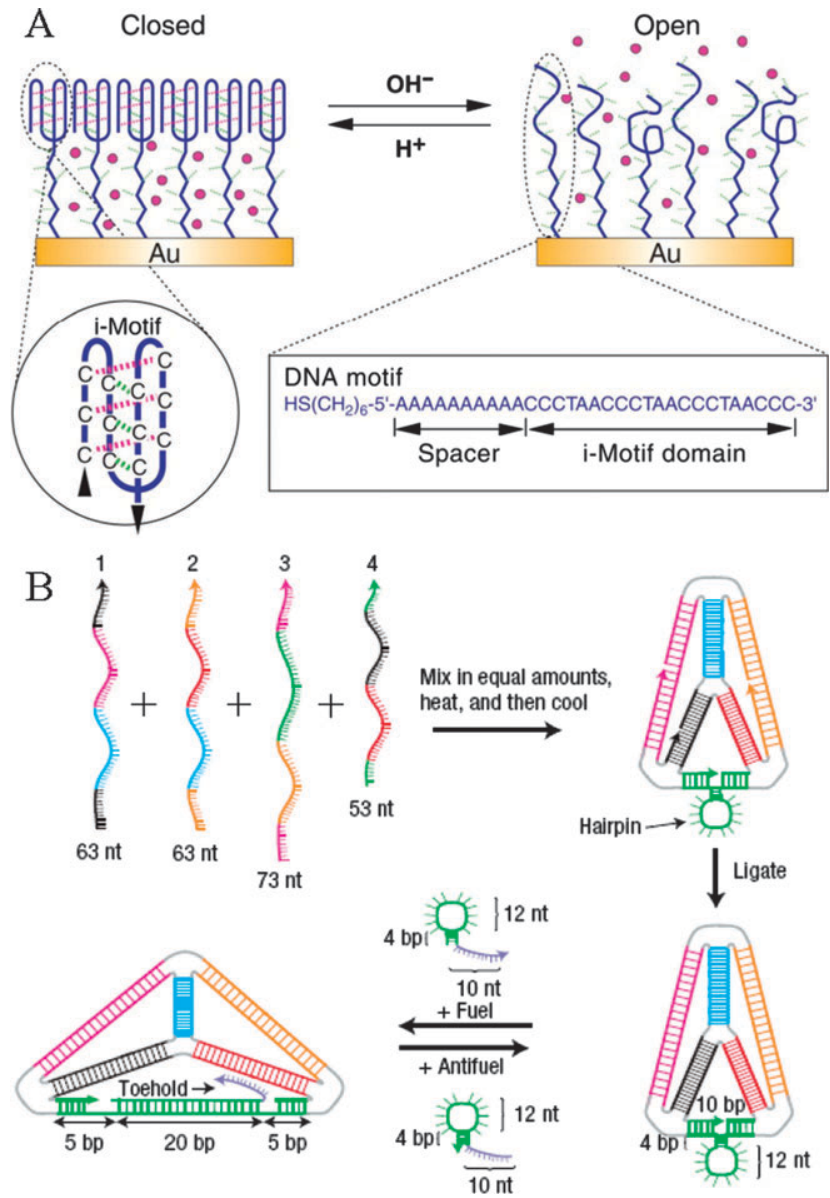

Fig. 14 DNA nanomachine based nanocontainers. (A) An i-motif DNA motors controlled nanocontainer. At low $\mathrm{pH}$, the $\mathrm{C}$-rich domain folds into i-motif structure and packs into a membrane impermeable for small molecules on a gold surface. At high $\mathrm{pH}$, the i-motif structures are transformed into ssDNA, making the packing density relatively loose to allow small molecules to diffuse freely (reprinted with permission from ref. 99; copyright 2007, Oxford Journals). (B) A reconfigurable DNA tetrahedron. The tetrahedron is formed by four strands and a hairpin segment has been incorporated into one edge. Based on "fuel-strands" strategy, the hairpin can be switched between open and closed states, leading to a volume change of the tetrahedron (reprinted with permission from ref. 101; copyright 2008, Nature Publishing Group).

of this device is that each i-motif DNA motor in the assembled monolayer is linked to the surface through a single stranded poly-(dA) ${ }_{n}$ spacer $(10 \leq n \leq 35)$. The function of spacers in the monolayer is important since they provide a low-density packing domain, which could be regarded as a nanocontainer. By changing $\mathrm{pH}$, the packing density of the upper domain (DNA motors domain) could be switched between high (densely packed i-motif conformations, closed state) and low (loosely packed ssDNAs, open state) states. At open state, small molecules could be released from spacer domains to the outer environment, while at closed state these molecules would be restricted in the nanocontainer protected by the upper closely packed DNA motors.

The encapsulation ability of 3D DNA assembled nanostructures ${ }^{100}$ have been studied by Turberfield's group 
using rigid DNA tetrahedra. ${ }^{15}$ The evolution of this strategy has led to reconfigurable DNA tetrahedra whose shapes change precisely and reversibly in response to specific molecular signals. ${ }^{101}$ As shown in Fig. 14(b), a hairpin segment has been incorporated into one edge of this new reconfigurable DNA tetrahedron. The edge containing hairpin is at its shortest $(10 \mathrm{bp}, 3.4 \mathrm{~nm})$ when the hairpin is in the closed state. By adding a fuel strand that opens the hairpin, the edge could be extended to its longest state (30 bp, $10.2 \mathrm{~nm})$. This transition will cause a volume change. A tetrahedron with two reconfigurable edges has also been built in this work.

The second strategy to control release by DNA nanomachines is to exert force to break substrate-target interactions. Simmel et al. have demonstrated this cyclically binding and releasing thrombins by G-quadruplex based nanomachines. ${ }^{102}$ It is well known that the G-quadruplex structure has a high binding affinity to the thrombin molecule. Using the same strategy to open G-quadruplex nanomotors, the addition of fuel-strands will disrupt the interactions between the G-quadruplex and thrombin molecules to realize the release of thrombins. The release kinetics has also been studied. ${ }^{103} \mathrm{In}$ a related work done by Sugiyama's group, ${ }^{104} \mathrm{pH}$ switching has been employed to control the release of the telomere-binding protein TRF 1 which has high affinity towards the i-motif structure; or the release of small G-quadruplex-binding molecules to impede progress of the polymerase.

\section{Conclusions and outlook}

In this review, we have summarized the development of DNA nanomachines in recent decades. The development of this field has demonstrated again the DNA is an important multipurpose material in nanotechnology other than its biological characteristics.

Looking towards the future, the current research on DNA nanomachines is still in its early stages and the most established systems are simple models. We here consider the following issues which might be the most important challenges for future development in this field: (1) experimental and theoretical studies on single DNA nanomachines leading to understanding of energy conversion mechanisms and entropy exchange with the environment; (2) a new power supplying method which could be easily incorporated into current silicon based nanodevices; (3) improvement of the reliability of DNA nanomachines; (4) directionally controllable movements; (5) multi-component DNA nanomachines with clear and interconnected energy transformation and mechanical response; (6) evaluation of biological and medical applications of DNA nanomachines. In summary, the anticipated development in this field will be fascinating and we believe DNA will play a more important role in nanoscience in the coming decade.

\section{Acknowledgements}

D. L. would like to thank Prof. Xi Zhang in Tsinghua University for helpful discussion and NSFC under grant No. 20725309, NSFC-DFG joint project TRR61 and MOST under grant No 2007CB935902 for financial supports.

\section{References}

1 N. C. Seeman, Nature, 2003, 421, 427-431.

2 N. C. Seeman, J. Theor. Biol., 1982, 99, 237-247.

3 N. C. Seeman and N. R. Kallenbach, Annu. Rev. Biophys. Biomol. Struct., 1994, 23, 53-86.

4 N. C. Seeman, Angew. Chem., Int. Ed., 1998, 37, 3220-3238.

5 N. C. Seeman, Nano Lett., 2001, 1, 22-26.

6 N. C. Seeman, Chem. Biol., 2003, 10, 1151-1159.

7 E. Winfree, F. R. Liu, L. A. Wenzler and N. C. Seeman, Nature, 1998, 394, 539-544.

8 C. D. Mao, W. Q. Sun and N. C. Seeman, J. Am. Chem. Soc., 1999, 121, 5437-5443

9 H. Yan, S. H. Park, G. Finkelstein, J. H. Reif and T. H. LaBean, Science, 2003, 301, 1882-1884.

10 P. W. K. Rothemund, Nature, 2006, 440, 297-302.

11 Y. G. Ke, S. Lindsay, Y. Chang, Y. Liu and H. Yan, Science, 2008, 319, 180-183.

12 K. V. Gothelf and T. H. LaBean, Org. Biomol. Chem., 2005, 3, 4023-4037.

13 J. H. Chen and N. C. Seeman, Nature, 1991, 350, 631-633.

14 Y. W. Zhang and N. C. Seeman, J. Am. Chem. Soc., 1994, 116, 1661-1669.

15 R. P. Goodman, I. A. T. Schaap, C. F. Tardin, C. M. Erben, R. M. Berry, C. F. Schmidt and A. J. Turberfield, Science, 2005, 310, 1661-1665.

16 W. M. Shih, J. D. Quispe and G. F. Joyce, Nature, 2004, 427, 618-621.

17 V. Balzani, A. Credi, F. M. Raymo and J. F. Stoddart, Angew. Chem., Int. Ed., 2000, 39, 3348-3391.

18 J. F. Stoddart, Acc. Chem. Res., 2001, 34, 410-411.

19 W. R. Browne and B. L. Feringa, Nat. Nanotechnol., 2006, 1, $25-35$.

20 E. R. Kay, D. A. Leigh and F. Zerbetto, Angew. Chem., Int. Ed., 2007, 46, 72-191.

21 M. Schliwa and G. Woehlke, Nature, 2003, 422, 759-765.

22 K. Kinbara and T. Aida, Chem. Rev., 2005, 105, 1377-1400.

23 X. P. Yang, A. V. Vologodskii, B. Liu, B. Kemper and N. C. Seeman, Biopolymers, 1998, 45, 69-83.

24 N. C. Seeman, Trends Biochem. Sci., 2005, 30, 119-125.

25 F. C. Simmel and W. U. Dittmer, Small, 2005, 1, 284-299.

26 P. Alberti, A. Bourdoncle, B. Sacca, L. Lacroix and J.-L. Mergny, Org. Biomol. Chem., 2006, 4, 3383-3391.

27 M. K. Berssenhirtz and I. Willner, Org. Biomol. Chem., 2006, 4, $3392-3401$.

28 J. Bath and A. J. Turberfield, Nat. Nanotechnol., 2007, 2, 275-284.

29 T. Liedl, T. L. Sobey and F. C. Simmel, Nano Today, 2007, 2, 36-41.

30 B. Yurke, A. J. Turberfield, A. P. Mills Jr, F. C. Simmel and J. L. Neumann, Nature, 2000, 406, 605-608.

31 B. K. Muller, A. Reuter, F. C. Simmel and D. C. Lamb, Nano Lett., 2006, 6, 2814-2820.

32 F. C. Simmel and B. Yurke, Phys. Rev. E, 2001, 63, 041913.

33 F. C. Simmel and B. Yurke, Appl. Phys. Lett., 2002, 80, 883-885.

34 H. Yan, X. P. Zhang, Z. Y. Shen and N. C. Seeman, Nature, 2002, $415,62-65$.

35 H. Zhong and N. C. Seeman, Nano Lett., 2006, 6, 2899-2903.

36 B. Chakraborty, R. Sha and N. C. Seeman, Proc. Natl. Acad. Sci, USA, 2008, 105, 17245-17249.

37 J. J. Li and W. Tan, Nano Lett., 2002, 2, 315-318.

38 P. Alberti and J.-L. Mergny, Proc. Natl. Acad. Sci, USA, 2003, 100, 1569-1573.

39 C. D. Mao, W. Q. Sun, Z. Y. Shen and N. C. Seeman, Nature, 1999, 397, 144-146.

40 R. P. Fahlman, M. Hsing, C. S. Sporer-Tuhten and D. Sen, Nano Lett., 2003, 3, 1073-1078.

41 D. Miyoshi, H. Karimata, Z.-M. Wang, K. Koumoto and N. Sugimoto, J. Am. Chem. Soc., 2007, 129, 5919-5925.

42 D. Liu and S. Balasubramanian, Angew. Chem., Int. Ed., 2003, 42, 5734-5736.

43 Y. Chen, S.-H. Lee and C. Mao, Angew. Chem., Int. Ed., 2004, 43, 5335-5338.

44 M. Brucale, G. Zuccheri and B. Samori, Org. Biomol. Chem., $2005,3,575-577$. 
45 R. Tashiro and H. Sugiyama, J. Am. Chem. Soc., 2005, 127, 2094-2097.

46 V. Viasnoff, A. Meller and H. Isambert, Nano Lett., 2006, 6, 101-104.

47 W. Q. Shen, M. F. Bruist, S. D. Goodman and N. C. Seeman, Angew. Chem., Int. Ed., 2004, 43, 4750-4752.

48 W. B. Sherman and N. C. Seeman, Nano Lett., 2004, 4, 1203-1207.

49 T. H. LaBean, H. Yan, J. Kopatsch, F. R. Liu, E. Winfree, J. H. Reif and N. C. Seeman, J. Am. Chem. Soc., 2000, 122, $1848-1860$.

50 J. S. Shin and N. A. Pierce, J. Am. Chem. Soc., 2004, 126, 10834-10835.

51 Y. Tian and C. D. Mao, J. Am. Chem. Soc., 2004, 126, $11410-11411$.

52 A. J. Turberfield, J. C. Mitchell, B. Yurke, A. P. Mills Jr, M. I. Blakey and F. C. Simmel, Phys. Rev. Lett., 2003, 90, 118102-11411.

53 S. J. Green, D. Lubrich and A. J. Turberfield, Biophys. J., 2006, 91, 2966-2975.

54 G. Seelig, B. Yurke and E. Winfree, J. Am. Chem. Soc., 2006, 128 , 12211-12220.

55 Y. Wang, Y. Zhang and N. P. Ong, Phys. Rev. E, 2005, 72, 051918.

56 D. Y. Zhang, A. J. Turberfield, B. Yurke and E. Winfree, Science, 2007, 318, 1121-1125.

57 S. Venkataraman, R. M. Dirks, P. W. K. Rothemund, E. Winfree and N. A. Pierce, Nat. Nanotechnol., 2007, 2, 490-494.

58 E. Gouin, M. D. Welch and P. Cossart, Curr. Opin. Microbiol., 1999, 8, 35-45.

59 Y. Chen, M. S. Wang and C. D. Mao, Angew. Chem., Int. Ed., 2004, 43, 3554-3557.

60 Y. Chen and C. D. Mao, J. Am. Chem. Soc., 2004, 126, 8626-8627.

61 J. D. Bishop and E. Klavins, Nano Lett., 2007, 7, 2574-2577.

62 P. Yin, H. Yan, X. G. Daniell, A. J. Turberfield and J. H. Reif, Angew. Chem., Int. Ed., 2004, 43, 4906-4911.

63 Y. Tian, Y. He, Y. Chen, P. Yin and C. D. Mao, Angew. Chem., Int. Ed., 2005, 44, 4355-4358.

64 J. Bath, S. J. Green and A. J. Turberfield, Angew. Chem., Int. Ed., $2005, \mathbf{4 4}, 4358-4361$.

65 T. Liedl and F. C. Simmel, Nano Lett., 2005, 5, 1894-1898.

66 V. Gaspar and K. Showalter, J. Am. Chem. Soc., 1987, 109, 4869-4876.

67 N. Makita, S. Inoue, T. Akaike and A. Maruyama, Nucl. Acids Symp. Ser., 2004, 48, 173-174.

68 S. W. Choi, N. Makita, S. Inoue, C. Lesoil, A. Yamayoshi, A. Kano, T. Akaike and A. Maruyama, Nano Lett., 2007, 7, $172-178$.

69 A. Maruyama, M. Katoh, T. Ishihara and T. Akaike, Bioconjugate Chem., 1997, 8, 3-6.

70 W. J. Kim, T. Akaike and A. Maruyama, J. Am. Chem. Soc., 2002, 124, 12676-12677.

71 X. Liang, H. Nishioka, N. Takenaka and H. Asanuma, ChemBioChem, 2008, 9, 702-705.

72 H. Liu, Y. Xu, F. Li, Y. Yang, W. Wang, Y. Song and D. Liu, Angew. Chem., Int. Ed., 2007, 46, 2515-2517.

73 D. Liu, A. Bruckbauer, C. Abell, S. Balasubramanian, D.-J. Kang, D. Klenerman and D. Zhou, J. Am. Chem. Soc., 2006, 128, 2067-2071.

74 T. Liedl, M. Olapinski and F. C. Simmel, Nano Lett., 2006, 45, $5007-5010$

75 S. Wang, H. Liu, D. Liu, X. Ma, X. Fang and L. Jiang, Angew. Chem., Int. Ed., 2007, 46, 3915-3917.
76 T. Sun, L. Feng, X. Gao and L. Jiang, Acc. Chem. Res., 2005, 38, 644-652.

77 Z. J. Gartner and D. R. Liu, J. Am. Chem. Soc., 2001, 123, 6961-6963.

78 Z. J. Gartner, B. N. Tse, R. Grubina, J. B. Doyon, T. M. Snyder and D. R. Liu, Science, 2004, 305, 1601-1605.

79 K. V. Gothelf, A. Thomsen, M. Nielsen, E. Clo and R. S. Brown, J. Am. Chem. Soc., 2004, 126, 1044-1046.

80 Y. Chen and C. Mao, J. Am. Chem. Soc., 2004, 126, 13240-13241.

81 S. P. Liao and N. C. Seeman, Science, 2004, 306, 2072-2074.

82 R. Chhabra, J. Sharma, Y. Liu and H. Yan, Nano Lett., 2006, 6, 978-983.

83 C. A. Mirkin, R. L. Letsinger, R. C. Mucic and J. J. Storhoff, Nature, 1996, 382, 607-609.

84 A. P. Alivisatos, K. P. Johnsson, X. G. Peng, T. E. Wilson, C. J. Loweth, M. P. Bruchez and P. G. Schultz, Nature, 1996, 382, 609-611.

85 P. Hazarika, B. Ceyhan and C. M. Niemeyer, Angew. Chem., Int. Ed., 2004, 43, 6469-6471.

86 Y. H. Jung, K.-B. Lee, Y.-G. Kim and I. S. Choi, Angew. Chem. Int. Ed., 2006, 45, 5960-5963.

87 W. Wang, H. Liu, D. Liu, Y. Xu, Y. Yang and D. Zhou, Langmuir, 2007, 23, 11956-11959.

88 J. Sharma, R. Chhabra, H. Yan and Y. Liu, Chem. Commun., 2007, 477-479.

89 Y. Wang, X. Li, X. Liu and T. Li, Chem. Commun., 2007, 4369-4371.

90 W. Shu, D. Liu, M. W. C. K. Riener, T. Strunz, M. E. Welland, S. Balasubramanian and R. A. McKendry, J. Am. Chem. Soc., 2005, 127, 17054-17060.

91 B. Ding and N. C. Seeman, Science, 2006, 314, 1583-1585.

92 C. M. Niemeyer, M. Adler, S. Lenhert, S. Gao, H. Fuchs and L. Chi, ChemBioChem, 2001, 2, 260-264.

93 A. H. Buck, C. J. Campbell, P. Dickinson, C. P. Mountford, H. C. Stoquert, J. G. Terry, S. A. G. Evans, L. M. Keane, T. J. Su, A. R. Mount, A. J. Walton, J. S. Beattie, J. Crain and P. Ghazal, Anal. Chem., 2007, 79, 4724-4728.

94 C. P. Mountford, A. H. Buck, C. J. Campbell, P. Dickinson, E. E. Ferapontova, J. G. Terry, J. S. Beattie, A. J. Walton, P. Ghazal, A. R. Mount and J. Crain, J. Phys. Chem. B, 2008 , 112, 2439-2444.

95 Y. Weizmann, M. K. Beissenhirtz, Z. Cheglakov, R. Nowarski, M. Kotler and I. Willner, Angew. Chem., Int. Ed., 2006, 45, 7384-7388.

96 M. K. Beissenhirtz, R. Elnathan, Y. Weizmann and I. Willner, Small, 2007, 3, 375-379.

97 B. Shlyahovsky, D. Li, Y. Weizmann, R. Nowarski, M. Kotler and I. Willner, J. Am. Chem. Soc., 2007, 129, 3814-3815.

98 L. Zhang, C. Feng, Z. Chen, L. Liu, K. Jiang, Q. Li and S. Fan, Nano Lett., 2008, 8, 2564-2569.

99 Y. Mao, D. Liu, S. Wang, S. Luo, W. Wang, Y. Yang, Q. Ouyang and L. Jiang, Nucleic Acids Res., 2007, 35, e33.

100 C. M. Erben, R. P. Goodman and A. J. Turberfield, Angew. Chem., Int. Ed., 2006, 45, 7414-7417.

101 R. P. Goodman, M. Heilemann, S. Doose, C. M. Erben, A. N. Kapanidis and A. J. Turberfield, Nat. Nanotechnol., 2008, 3, 93-96.

102 W. U. Dittmer, A. Reuter and F. C. Simmel, Angew. Chem., Int. Ed., 2004, 43, 3550-3553.

103 A. Reuter, W. U. Dittmer and F. C. Simmel, Eur. Phys. J. E, 2007, 22, 33-40.

104 Y. Xu, Y. Hirao, Y. Nishimura and H. Sugiyama, Bioorg. Med. Chem., 2007, 15, 1275-1279. 